\title{
ARTICLE
}

\section{Epistemic Self-Trust: It's Personal}

\author{
Katherine Dormandy \\ Department of Christian Philosophy, University of Innsbruck, Austria \\ Email: katherine.dormandy@uibk.ac.at
}

(Received 30 December 2019; revised 29 September 2020; accepted 9 October 2020)

\begin{abstract}
What is epistemic self-trust? There is a tension in the way in which prominent accounts answer this question. Many construe epistemic trust in oneself as no more than reliance on our sub-personal cognitive faculties. Yet many accounts - often the same ones - construe epistemic trust in others as a normatively laden attitude directed at persons whom we expect to care about our epistemic needs. Is epistemic self-trust really so different from epistemic trust in others? I argue that it is not. We certainly do rely on our cognitive faculties to achieve epistemic ends; but I argue that we also have the normatively rich sort of epistemic trust in ourselves. Moreover, there is a theoretical need for this normatively rich notion of epistemic self-trust: positing it yields the best account of how we secure important epistemic goods, including knowledge and recognition as knowers. I argue this by giving an account of epistemic trust in others and showing that it can be generalized to epistemic trust in oneself.
\end{abstract}

Keywords: Self-trust; epistemic trust; epistemic self-trust; epistemic recognition

\section{Introduction}

Self-trust is crucial to our epistemic lives. We need to trust ourselves when we acquire knowledge, and when we take the risk of testifying our knowledge to others. But what is epistemic self-trust? A common answer is that a person epistemically trusts herself when she relies on her sub-personal cognitive faculties (Foley 2001; Hinchman 2012; Zagzebski 2012; Fricker 2016; Tanesini 2020).

But if this is so, then epistemic self-trust is a different kind of thing entirely from epistemic trust in others. For epistemic trust in others, like trust in others more generally, involves a relationship in which the truster supposes that the trustee cares about his needs, and which is governed by interpersonal norms (Baier 1986; Jones 1996; Hinchman 2005; Faulkner 2007). Mere reliance on one's sub-personal faculties cannot be like this: faculties neither care nor answer to normative expectations.

I propose a richer account, on which epistemic self-trust is the same kind of thing as epistemic trust in others. Although we rely on our cognitive faculties, we do - and must do - more than this. We must care about our own epistemic needs and hold ourselves to normative expectations in meeting them. Epistemic self-trust must be like this if it is to help secure epistemic goods, including knowledge and recognition as a knower. 
I begin with a general account of trust in others, and argue that trust tends to be more effective than mere reliance at obtaining one's ends, epistemic or otherwise (section 2). I then discuss prominent accounts that construe epistemic self-trust as mere reliance on one's cognitive faculties. Many of these exhibit a tension that - I argue - is best resolved by construing epistemic self-trust, instead, in the richer sense that applies to epistemic trust in others (section 3). My argument that epistemic selftrust is the same kind of thing as epistemic trust in others has three premises. First, I argue that in pursuing epistemic ends we rely on ourselves, not just our cognitive faculties (section 4). Second, I argue that this reliance on ourselves can, and often does, have the additional features that make for epistemic self-trust - so epistemic self-trust, in the richer sense, is a psychological possibility (section 5). Finally, I argue that trusting ourselves epistemically, rather than merely relying on ourselves, achieves better epistemic results and so is what our epistemological theories need (section 6). The result is an account of epistemic self-trust that can be integrated with social-epistemological accounts of epistemic trust in others.

\section{Trust and its efficacy}

\subsection{Trust vs. reliance}

Trust in other people is standardly taken to entail reliance on them. Reliance can be construed as the following three-place relation:

Reliance: $A$ relies on $B$ for $x$ just in case $A$ premises her actions on $B$ 's bringing about $x$, where $A$ 's interests are harmed if $B$ does not do so. ${ }^{1}$

$A$ here is a person, and $x$ is a state of affairs. ${ }^{2} B$ could be an object or a person. You can rely on a shelf to hold your books, or on the bus driver to drive her usual route through your neighborhood. When $B$ is a person, $A$ simply supposes that $B$ will act in a predictable way.

$A$ 's premising her actions on $B$ 's bringing about $x$ amounts to $A$ 's using the following proposition as a premise in a practical argument:

\section{$B$ will bring about $x$.}

The practical argument concludes with $A$ 's deciding to involve $B$ in her plan to achieve $x$.

You can premise your actions on someone's or something's doing something without relying on her or it. For example, you might have an alternative plan in place that is nearly as likely to obtain $x$ should $B$ not deliver. (The premise would be something like, " $B$ may bring about $x$ and this will save me some trouble, but if she or it doesn't, then the means are in place for me to bring about $x$ instead by $\varphi$-ing".) You rely on $B$, in contrast, to the extent that you lack an alternative means or plan to obtain $x$. Thus reliance admits of degree, and to the degree that you rely on the person or thing, you are vulnerable to her or it to do what you are relying on her or it to do.

$A$ is better off if she has sufficient evidence to believe the premise $B$ will bring about $x$. But she need not believe it; she might simply assign it a higher probability than she assigns to other possible ways of achieving $x$. This probability might even fail to exceed

\footnotetext{
${ }^{1}$ Thanks to an anonymous reviewer for Episteme for pressing the need for this qualification about the harming of A's interests, and for this formulation of it.

${ }^{2} \mathrm{I}^{\prime} l l$ use phrases such as "obtaining $x$ " and "achieving $x$ " as shorthand for "the end of bringing about state of affairs $x . "$
} 
$1 / 2$. For example, you might rely on a bridge to hold your weight even though it is dangerously rickety, because crossing it is the only possible way to escape a vengeful enemy. Practical reasoning need not involve belief in the premises. All that is needed for practical reasoning is for the premises of the argument to motivate the agent to act (Alvarez 2010: 366-73), and belief is not the only propositional attitude that can motivate. $A$ might for instance hope that $B$ will bring about $x$, or have an attitude akin to pretending that $B$ will bring about $x$ (where pretense has a similar cognitive and neurological structure to belief). One might worry that the decision to involve $B$ will not be rational if $A$ does not believe $B$ will bring about $x$. In response, if $A$ values $x$ enough, and involving $B$ is the best way to achieve $x$ (perhaps among a bad lot), then $A$ 's involving $B$ is rational.

So much for reliance; what is trust? Some construe trust as equivalent to reliance (Coleman 1990; Hardin 1993). But there is another, richer, form of trust, which is partly constituted by reliance but has other features too. A crucial one is that, whereas mere reliance can be directed toward a person or a thing, trust can only be directed toward a person. The reason is that trust (on standard accounts) involves certain essentially interpersonal features. I will first list two interpersonal features of the truster, ${ }^{3}$ and will say more later about the trustee:

(i) Psychological Feature of the Truster: The truster premises his actions not just on the trustee's bringing about $x$, but on her doing so because she cares about the truster or his need for $x$.

(ii) Normative Feature of the Truster: The truster has certain normative expectations of the trustee, prominently the expectation of her to do her best within reason to bring about $x$; and the truster is answerable to certain normative expectations of the trustee's.

One can only have these features in relation to a person. It makes sense to expect persons, but not shelves, to care about you or your need, and to be subject to normative expectations.

Some accounts of trust embrace both features, others just one. I'll suppose that a prototypical case of trust involves both, not least because it also presents a tougher hurdle for my argument. I want to show that epistemic self-trust is trust, as opposed to mere reliance; if I can show that epistemic self-trust exhibits both features, then this will satisfy everybody, including those who would be happy with only one.

(i) says that the truster premises his actions not just on the trustee's doing something such that her not doing it would harm his interests (as suffices for reliance), but on her doing it in a certain way or for a certain reason - namely with an affective response that I have called caring for the truster or his need. Baier (1986) says for instance that the attitude that the truster supposes the trustee to have is one of good will toward him, or at least toward a common project. Jones (1996), Faulkner (2007), McMyler (2011), and Hinchman (2012) hold that the attitude is an affective response of the truster's to the fact that the truster is depending on her. Here too, I do not suppose that the truster need believe that the trustee cares about him in order to premise his actions upon her doing so, though in standard cases he probably does believe this.

(ii) says that the truster has normative expectations of the trustee, and that he is in turn answerable to the trustee's normative expectations. A normative expectation is an expectation of someone - the ascription of an "ought" to her. Normative expectations can be unjustified or subjective; think of an overly demanding partner or boss. But they

\footnotetext{
${ }^{3}$ For (i) see e.g. Baier (1986), Jones (1996), and Faulkner (2007); for (ii) see e.g. Hinchman (2005), Faulkner (2007), and Jones (2017), and - I would argue - Hawley (2014).
} 
can also be appropriate: they can correspond to norms that are operative in the situation. Friendship comes with norms, for example, and so do relationships of trust (on which more below). A salient, perhaps definitive, norm of trust - at least when the trustee accepts the trust - is that the trustee should do her best within reason to bring about the event for which she is being trusted, and that the truster is entitled to feel betrayed if she culpably fails (Holton 1994). Another example is the norm that makes it appropriate, at least often, for the truster to be grateful should the trustee come through, and for the trustee to resent ingratitude on the truster's part. And there is the norm that the trustee should decline to accept trust if she is not competent to discharge it. ${ }^{4}$

Normative expectations stand in contrast to predictive expectations, expectations that someone will do something. For simplicity we can understand a predictive expectation as a belief. Normative and predictive expectations often go together: if you expect of me that I'll do something, it is often reasonable to expect that I will do it. But the two types of expectation can come apart. For example, you may expect of me that I'll arrive on time (because arriving late would violate norms of politeness); but unfortunately you do not believe that I will do so, because I am chronically disorganized. By contrast, you might expect that my coworker will arrive early, because she dreads being late, but you do not expect it of her that she will arrive early, since earliness would be supererogatory.

So trust, unlike reliance, involves normative expectations. What about predictive expectations? Take reliance first. I have said that reliance, though it standardly involves the belief (i.e. the predictive expectation) that the other party will do what you are relying on her to do, does not entail such a belief. The same applies to trust. In standard cases, trust tends to involve believing that the trustee will do the thing in question, among other reasons because she is competent and motivated to do so. But I will not assume that such a belief is constitutive of trust. I want to leave open the possibility that you can trust someone without believing that she will come through. The reason most relevant here, analogous to the case of reliance, is that trusting someone could be the best of a bad lot of options for achieving the end in question: you take the trustee to be unlikely to come through (say, because she is not very competent), but you have no better alternative. As in the case of reliance, your doxastic attitude toward the practical-reasoning premise The trustee will come through because she cares about me or my project, if you do not outright believe it, could be hope or something like pretense. $^{5}$

Features (i) and (ii) only apply to the truster. We need a word about the trustee. For trusting someone is not enough to make for a trust relationship. After all, the trustee

\footnotetext{
${ }^{4}$ Views differ over what kind of norms the norms of trust are; they might be social, moral, or sui generis (i.e. arising from the kind of thing that trust is); for discussion see Jones (2017) and Dormandy (2020).

${ }^{5}$ Some argue that predictive expectations are constitutive of trust (and reliance); that is, that an attitude does not count as trust (or reliance) if you fail to believe that the other party will come through (Coleman 1990; Hardin 1993; Hieronymi 2008; McMyler 2011; Nickel 2012; Keren 2014). In support of this view, consider a parent who leaves her teenager alone with the house for the weekend for the sake of teaching him responsibility. If the parent does this without believing that he will keep the house in one piece, she does not really trust him, but merely pretends to. But in response, in support of the view that trust is compatible with not believing that the other party will come through, imagine this parent saying to the teenager, "On the basis of your past behavior there is a good chance you will wreck the house, but this one last time I'll trust you anyway". This seems a perfectly sincere thing to say. It is difficult to adjudicate this debate without its dissolving into a clash of intuitions. But fortunately, the present paper does not require taking sides. Readers who think that trust entails belief that the trustee will come through can still accept the paper's main claim, that epistemic self-trust is a matter of trust in the robust sense described here. Such readers will simply call fewer things "trust" than I do.
} 
might not accept your trust - indeed, she might even be unaware that you are trusting her. (Misunderstandings and unspoken assumptions are commonplace.) In order for there to be a trust relationship, features (i) and (ii) must be in place, but in addition the trustee must accept the trust. Someone who accepts trust, I suggest, has the following two features:

$\left(i^{\star}\right)$ Psychological Feature of the Trustee: The trustee is disposed to care about the truster or the need that he trusts her for.

$\left(i i^{*}\right)$ Normative Feature of the Trustee: The trustee commits to meeting the truster's normative expectations (specifically: those legitimated by the trust relationship), including to doing her best within reason to come through for the truster; and she is entitled to have certain normative expectations of the truster in return.

A trust relationship requires, in addition to the trustee's accepting the trust, that both parties be aware of this trusting cooperation - though the communication of this mutual awareness can remain implicit. It is a trust relationship, rather than trusting someone irrespective of whether she accepts your trust, that gives trust the advantages that I will argue that it has over mere reliance (section 2.2).

Mere reliance can involve a relationship too, but this is a relationship in which the psychological and normative features of trust relationships are lacking. Someone who merely relies does not suppose that the other party is disposed to care about him or his need, and he has no normative expectation of her vis-à-vis the provision of his need. And someone who is merely relied on is not disposed to care about the relier or his need, and she does not place herself under the norms of trust. Mere reliance (and being merely relied upon) might, for example, be purely transactional. Trust relationships, by contrast, are essentially interpersonal: they come with interpersonal sentiments (or at least dispositions to experience them) and are governed by norms pertaining to the treatment of persons.

So I am understanding a trust relationship as one in which one person trusts another, exhibiting features (i) and (ii), and the other person accepts his trust, exhibiting features ( $\left.i^{\star}\right)$ and (ii ${ }^{*}$ ). Mere reliance, in contrast, arises when the relier exhibits neither (i) nor (ii) and the reliee exhibits neither $\left(\mathrm{i}^{\star}\right)$ nor $\left(\mathrm{ii}^{\star}\right)$. This is an artificial distinction; gray areas arise in which some of the features of a trust relationship are present without the others. To keep matters simple, I will ignore such cases, and compare only cases of trust in which both features are present, and cases of mere reliance in which neither feature is present. $^{6}$

\subsection{The causal efficacy of trust}

Trusting and relying are both ways in which a person might aim to bring about an end. But a relationship of trust, all else equal, is a more effective way to do so than one of mere reliance. To compare like with like, I will limit the discussion to cases in which the one being relied on is a person.

The claim that I will defend is this:

Efficacy-of-Trust Claim: Being in a trust relationship with someone vis-à-vis some end strongly tends to be a more effective way to obtain that end than merely relying on that person is.

\footnotetext{
${ }^{6}$ Gray areas also arise in discerning exactly what one person trusts another for, as trust relationships are often not spelled out contractually (Baier 1986: 233-42).
} 
In other words, a trust relationship strongly tends to raise the probability of achieving the relevant aim beyond what it would be in a case of mere reliance. For example, suppose that your aim is to get home from the train station. Given the options of trusting or relying on your colleague to pick you up, trusting him is typically the better bet. ${ }^{7}$ I have three reasons for the efficacy-of-trust claim.

The first draws on features $\left(\mathrm{i}^{\star}\right)$ and $\left(\mathrm{ii}^{\star}\right)$ of accepting trust. Both tend to actively dispose the trustee to bring about the end for which she is being trusted. Caring for someone or his need (as in $\left(i^{*}\right)$ ) motivates you to help him if you can; and placing yourself under normative pressure (as in (ii $\left.{ }^{\star}\right)$ ) motivates you to carefully gauge your competence and take other measures to ensure that you can come through.

The second reason is that being trusted tends to have a psychological effect on the trustee. The very fact that one person trusts another tends to increase the latter's motivation to come through from whatever it would be otherwise, including motivating her to accept his trust to begin with (Faulkner 2007; Hinchman 2012; Alfano 2016; D'Cruz 2019). Why? By trusting someone, a truster signals that he regards her as trustworthy: as competent and motivated to come through. Other people's views of a person influence her own self-concept (Alfano 2016), and a person's self-concept in turn inclines her to act in ways that conform with it (Harmon-Jones 2019: Chapter 1). So if someone signals by trusting a person that he regards her as trustworthy, this inclines her to be trustworthy, raising the probability that she will come through above what it would be if the other party merely relied on her.

One might deny that reliance is particularly worse than trust. After all, a given case of mere reliance might possess probability-raising features of its own. One is that having someone rely on you can signal that he regards you as reliable; this can influence you to see yourself as reliable and thus to behave reliably. Another is that the person being relied on may be under some degree of pressure or coercion, or have strong incentives to come through, for example due to a threat or legal or reputational consequences for failure, or the prospect of a paycheck for success. In such cases, mere reliance could be more efficacious than trust would be.

Let's take these possibilities in turn. In response to the idea that having someone rely on you can influence you to behave reliably, the two reasons sketched above show that trust enjoys special advantages, as the trustee is apt to be especially disposed to help the truster. On top of this - and this is my third reason for the efficacy-of-trust claim mere reliance can have disadvantages in contrast to trust. The disadvantages arise in cases where trust might have been expected to materialize but didn't. Imagine that you are buying real estate, but decline to trust the listing agent, extending her no more than your reliance. For example, you do not premise your actions on her caring about you or your need. This may be because you actively distrust her, or because you merely lack the two additional features of trust. ${ }^{8}$. Whatever your attitude, the bare fact that you do not trust her may signal distrust to her. Why? Because, given your frequent interactions with her over an extended period, a relationship of trust might otherwise have naturally developed. That it has not is thus conspicuous. A tempting explanation from the listing agent's point of view is that your attitude toward her is negative rather than neutral. We are biased to see the world, especially others' intentions toward us, in black-and-white categories instead of gray tones, and to think something negative or

\footnotetext{
${ }^{7}$ The efficacy-of-trust claim concerns cases in which your main aim is to obtain the thing that you are trusting (or relying) for, such as a lift from the station. There are other cases in which you might have a "higher" aim, such as helping your colleague grow in responsibility, or practice his driving. The efficacy-of-trust claim says nothing about such cases.

${ }^{8}$ Hawley (2014) shows why distrust is more than just the absence of trust.
} 
positive, rather than something neutral. Your lack of trust in the listing agent, then, is apt to prime her toward a self-concept as an untrustworthy person - and this, as we saw, is apt to influence her behavior accordingly, making her less likely to take your interests into account. Where trust is conspicuously absent, then, you may (wittingly or unwittingly) signal distrust - which lowers the probability that the party being relied on will come through.

What about incentives, pressure, or coercion? Given that cases of mere reliance often feature these (or strongly incentivize cooperation), this surely tips the balance in favor of the efficacy of mere reliance over trust. We may agree that it surely does in some cases. Someone who refuses to accept or discharge trust is still apt to respond to these.

My first response is that this is one reason why the efficacy-of-trust claim states a tendency rather than an unconditional law. Some situations can override this tendency. When a given trust relationship would otherwise not be efficacious, and when such additional features are in place, mere reliance is apt to be more efficacious.

But my second response is that, even if pressure or coercion (or at least some forms of strong incentive) obtains what you want, they may do so at the cost of destroying any trust there may have been; this will forfeit any of the abovementioned benefits, to say nothing of making the other party less likely to offer uncoerced help in the future.

My third response, however, is that, where pressure, coercion, or strong incentives do not forfeit the benefits of trust, they are not necessarily alternatives to trust at all. On the contrary, in certain cases they can make trust more efficacious than otherwise. Consider cases in which the source of pressure or possible coercion is a neutral third party, such as the state underwriting a fair legal contract. If there is already a measure of good will between the parties, they might not think twice about this, yet it will discretely guarantee the trust commitment. In fact, each party may trust the other more because the other one has cared enough to seal his commitment legally. Family business enterprises, marriages, or real estate deals between friends are often like this. The gentle mix of trust and third-party pressure or coercion can make trust more efficacious than otherwise - without the pressuring or coercive mechanism ever being resorted to. ${ }^{9}$ The effect of pressure or coercion in a given situation is a case-by-case matter, but by itself it does not support the general efficacy of mere reliance over trust.

In summary, trusting someone for something (where she accepts your trust) is all else equal more likely to secure you that thing than merely relying on her for it. The first reason is definitional: trust relationships have additional features to motivate the trustee that relationships of mere reliance lack. The second is psychological: the interpersonal dynamic that arises when one person trusts another influences the latter to be trustworthy. The third too is psychological: when trust is conspicuously absent, it can signal distrust and raise the probability of untrustworthiness. Finally, specific cases aside, the fact that mere reliance can come with pressure or coercion does not give it any general advantage over trust.

\section{Epistemic trust in others and epistemic self-trust}

Our destination is an account of epistemic trust in oneself. En route I have characterized trust in other people, and have argued that trust strongly tends to be more effective than mere reliance at achieving one's desired ends. We have one more stop: an account of epistemic trust in other people.

\footnotetext{
${ }^{9}$ If the mechanism is resorted to, the relationship may lose its character as trust and become mere reliance; but the fact that the mechanism is in place is a subtle encouragement to avoid letting things get so far.
} 
What makes trust epistemic is that the ends for which one trusts are epistemic goods. A classic form of epistemic trust is testimony. Here, one person, whom we may call the hearer, trusts another, whom we may call the speaker, ${ }^{10}$ for epistemic goods such as knowledge, truth, or justified belief. These belong to a class of epistemic goods I have called representational (Dormandy 2020: 247-8) on the grounds that they portray the world as being a certain way or indicate whether a state that does so is accurate. Other examples of representational epistemic goods are evidence, probability, and reliability.

In contrast to representational goods, which a hearer trusts a speaker for, there is a second type of epistemic good for which a speaker trusts a hearer. I have elsewhere called these recognitional (Dormandy 2020: 247-8). These are forms of positive epistemic recognition that a speaker deserves. Examples include being acknowledged and responded to as a legitimate epistemic agent, receiving due credit for your ideas, not being interpreted uncharitably, and so forth. Whereas representational goods are what someone is after who wants knowledge (or truth, or the like), recognitional goods are what someone is after who wants to share her knowledge (or truth, etc.).

Epistemic trust in others, then, is a matter of trusting others for knowledge or other representational goods, or for epistemic recognition in response to articulations of your knowledge.

Now that we have an account of epistemic trust in others, we are finally in a position to discuss epistemic trust in oneself. The literature treats this very differently from epistemic trust in others. One difference is that the literature tends to focus on representational goods, such as knowledge or true belief, with little if any discussion of trusting oneself for epistemic recognition. I will return to this issue in section 4. But for now I will focus on another way in which the literature treats epistemic self-trust differently from epistemic trust in others. It is this: most views do not construe epistemic self-trust as trust in the rich sense characterized by the psychological and normative features above, but as mere reliance, characterized by their absence. To see this, note that most accounts construe the object of epistemic self-trust not as a person - i.e. not as oneself - but as one's sub-personal cognitive faculties. Impersonal objects, we saw in section 2, are not candidates for trust, but only for reliance. Standard views, then, construe self-trust in terms of the pared-down notion of mere reliance.

For example, Richard Foley (2001: 3) says that epistemic self-trust is directed at one's "opinions and faculties". Linda Zagzebski (2012: 36) says, "I trust my epistemic faculties to get me to the truth. Trusting myself in this sense is like trusting my car". Edward Hinchman (2012: 77) says that when you epistemically trust yourself, you "rely on your epistemic faculties", and Elizabeth Fricker (2016: 154) says that "[t]he core phenomenon of epistemic self-trust consists in one's ungrounded reliance on one's cognitive faculties reliably to yield one true beliefs". Alessandra Tanesini (2020: 218-19) says that epistemic self-trust is composed in part of "dispositions to rely on the deliverances of one's epistemic faculties and abilities".

Yet on some of these views, the specter of personal trust still haunts, resulting in internal tension. For example, in the same work in which Zagzebski says that "I trust my epistemic faculties to get me to the truth. Trusting myself in this sense is like trusting my car" (2012: 36), she characterizes a self as "conscious of itself" and "the inner world of a person" (2012: 29). If this is what a self is, then it is at best strange that she would see the self's contribution to knowledge acquisition as analogous to that of a tool or machine. As for Hinchman's view, the tension is closer to an outright

\footnotetext{
${ }^{10}$ I use "speaker" and "hearer" for simplicity, though the more general terms "communicator" and "audience" are more precise.
} 
contradiction. We saw that, on his view, when you trust yourself epistemically, "you rely on your epistemic faculties" (2012: 77). Yet he claims in addition that epistemic self-trust is simply the relation of epistemic trust, "realized intrapersonally" (2012: 77). This is problematic, because the relation of epistemic trust, he says in the same paper, is a "distinctively epistemic species of care" (2012: 80). Yet epistemic faculties - the objects of epistemic self-trust for Hinchman - are sub-personal and hence not the sorts of things that can care for you. Hinchman cannot simultaneously maintain that epistemic selftrust is an instance of the caring relation of epistemic trust, while also maintaining that what you trust is no more than your cognitive faculties.

So even some who construe epistemic self-trust as mere reliance on one's cognitive faculties do not seem entirely comfortable with this idea. This discomfort is to my mind well-placed. The problem is not that epistemic self-reliance has no epistemic work to do; it does. We need it to form beliefs, and (as many of the above authors rightly argue), it had better be rational if any of those beliefs are to be rational. Moreover, epistemic self-reliance, being merely necessary but not sufficient for epistemic self-trust, is easier to come by and justify. ${ }^{11}$ So epistemic self-reliance is important. The problem lies in equating it with epistemic self-trust. This equation conflates two importantly distinct phenomena. We thus risk missing the important epistemic job performed by epistemic self-trust, where this is trust in oneself qua person.

I will defend the existence and importance of epistemic self-trust in this richer sense. First, I argue that we rely on ourselves for epistemic ends, not just on our cognitive faculties (section 4). Second, this reliance on ourselves can, and often does, have the additional features that make for epistemic self-trust (section 5). Third, epistemic self-trust is theoretically important because it promotes epistemic aims more effectively than mere self-reliance; that is, the efficacy-of-trust claim applies to epistemic self-trust too (section 6).

\section{Epistemic reliance on oneself, not just on one's faculties}

We certainly can and do rely on our cognitive faculties to obtain epistemic goods. But we also rely on ourselves.

Consider representational epistemic goods. In obtaining knowledge, evidence, true beliefs, and the like, much of your cognition works automatically, below your conscious awareness. Your sensory apparatus sends signals to your brain, which processes them into thoughts and attitudes, some fully conscious and others implicit. The self plays no direct role in these processes, but it plays an indirect one. Your values, intentions, and beliefs, for example, influence the content of the (other) thoughts and attitudes that your brain synthesizes from sensory signals. And these in turn shape the experiential evidence that you receive, both by directing what you notice in a given situation (Chabris and Simons 2011: Chapter 1) and by coloring how you perceive things that you do notice (Zeimbekis and Raftopoulos 2015). The thoughts and attitudes synthesized by your brain (and indirectly influenced by yourself) also influence the beliefs that your experiences deliver, as well as the range of any further beliefs that you take these to make probable.

The self also has a direct role to play in obtaining representational epistemic goods. It has - you have - a say in determining the situations that you find yourself in and thus the sort of information that you are exposed to; you also (alongside the abovementioned implicit factors) influence where to direct your attention in a given situation. Further, when you receive evidence, you must sift the valuable from the worthless, weigh up

\footnotetext{
${ }^{11}$ Thanks to a reviewer from Episteme for pressing the importance of epistemic self-reliance.
} 
conflicting evidence, and so forth. You must also decide whether a given issue is worth thinking through more carefully. You can direct your inquiry by asking (or neglecting to ask) certain questions. And it is you who decides - given opportunity constraints whether to hone your cognitive faculties to be more reliable: developing critical-thinking skills, getting glasses, taking an implicit bias test to pinpoint distortions in your perception of different testifiers, reading widely on issues that matter to you, even eating healthily to maximize your cognitive potential. In doing these things you of course rely on your cognitive (and other) faculties, but managing them, and being the kind of person whose influence on your implicit cognitive processes is epistemically beneficial, is your responsibility.

The importance of epistemic responsibility is not lost on the authors of the epistemic self-trust literature - including those who construe epistemic self-trust as mere reliance on one's faculties. For example, both Foley (2001) and Zagzebski (2012) argue that reliance on one's cognitive faculties is rational; and in response to the objection that their view uncritically licenses any beliefs delivered by one's faculties, inviting dogmatism or worse, both authors appeal to epistemic responsibility. Foley calls it critical self-reflection, and Zagzebski calls it conscientiousness. But both claim that the agent himself, if he is to prevent uncritical dogmatism, not only can, but must, exercise a managerial function in operating his cognitive faculties. Epistemic responsibility thus plays a pivotal role in their views of rational epistemic self-reliance. This makes it particularly odd that Foley and Zagzebski construe epistemic self-trust as mere reliance on one's faculties, as opposed to reliance on (or indeed trust in) oneself qua epistemic agent. When we seek to obtain representational epistemic goods, it is not only our cognitive faculties that we rely on, but ourselves - among other things, to exercise epistemic responsibility.

The same holds for recognitional epistemic goods: to obtain them you must rely on yourself, not (just) your faculties. Consider a situation in which you testify to a hearer. There are at least two functions that your self performs. First, where epistemic recognition hangs on the quality of your testimony (truth, well-foundedness, relevance, completeness, communicative efficacy, etc.), it is you, at the helm of your cognitive and other faculties, who bear responsibility for that quality. You have control over whether you deserve epistemic recognition. Second, it is not just your faculties, but you - responsibly managing them - who must judge whether a given (potential) hearer can be relied on, or indeed trusted, to respond with appropriate recognition.

But it is not just in judging whether others will epistemically recognize you that you must rely on yourself. You must also rely on yourself for epistemic recognition from yourself. Think of a student who, though he studied competently for an exam, suffers from low self-esteem, and so enlists a personal coach or therapist to help improve his self-esteem and thus his performance. What he is trying to learn is to grant himself the epistemic recognition that he deserves. To avoid self-sabotage before and during the exam, he will have to rely on himself for this recognition. His cognitive and other faculties can help, but they are just the tools in his hands.

In summary, whether the epistemic goods that you need are representational or recognitional, it is you yourself, and not just your faculties, on whom you rely.

\section{Epistemic trust can be directed at oneself}

That we can epistemically rely on ourselves does not imply that we can epistemically trust ourselves, let alone that we can have a trust relationship with ourselves. This section aims to establish that we can. Not only is an epistemic-trust relationship with ourselves psychologically possible, it is a standard and healthy way of relating to oneself. 
The first step is to argue that the two characteristic features of trust, (i) the psychological and (ii) the normative, can apply to someone who relies on himself epistemically. The second is to argue that they apply to him in such a way that he accepts his epistemic self-trust: $\left(\mathrm{i}^{\star}\right)$ that he cares about himself or his epistemic needs, and (ii $\left.{ }^{\star}\right)$ that he subjects himself to the norms of trust.

First, then, let's look at whether a person's self-reliance can amount to self-trust. I'll start with reliance in general and then turn to reliance for epistemic goods.

Consider (i) the psychological feature of trust: that the truster premises his actions on the supposition that the trustee will bring about his desired end because she cares about him or his need for it. When a single person is both truster and trustee, this amounts to premising your actions on the supposition that you yourself will respond favorably because you care about yourself or about your own need. Having this supposition about oneself is not only psychologically possible, but is a component of healthy self-esteem. Acting as if your needs are worth recognizing, indeed sufficiently worth it for you to go to some trouble to meet them, springs from regarding yourself as valuable enough to deserve this sort of attention and care.

This holds when the self-trust is for epistemic goods. Consider representational goods. When you rely on yourself (say) to scrutinize evidence and avoid bias, you can base this reliance on the supposition that you (qua trustee) will care about and will competently meet your own need for representational goods. We can trust ourselves for recognitional goods too: you can trust yourself to seek out respectful hearers or to give yourself epistemic recognition. Either way you can premise your reliance for recognition on the idea that you care about your own need for it. This is what a person aims to do, for example, if she courageously steps out to give a professional talk in spite of stage fright. She has trusted herself to seek out an appropriate forum of hearers, and for the self-belief needed to succeed in this high-stakes knowledge-sharing situation. Doing this signals a healthy self-esteem with respect to her epistemic needs and merits.

Let's turn to (ii) the normative feature of trust: the truster holds the trustee to the normative expectations of a trust relationship, prominently to do her best within reason to bring about the end that he is trusting for. This can apply within the self. You can have expectations of yourself to do your best to deliver something that you need, such as getting out of the house in time to make the train. If you let yourself down, reactive attitudes such as self-reproach are fitting (though hopefully self-forgiveness can follow). If you come through for yourself, then attitudes such as self-congratulation, or gratitude toward yourself, are well placed - or so personal coaches and therapists assure us. Indeed, such people may actively encourage us to hold ourselves to high expectations.

It is possible to hold oneself to high expectations specifically for obtaining epistemic goods. Consider representational goods. You can normatively expect yourself to do high-quality research on matters that you care about, and you can feel betrayed or let down by yourself if you make a sloppy error. As for recognitional goods, you can hold yourself to the expectation (say) of contributing confidently to a committee meeting, for you deserve to be heard; and you may feel that you let yourself down if you meekly allow yourself to be talked over.

So the psychological and normative features of trust can apply within a single person, including for epistemic goods. You can act on the supposition that you care about and will meet your own epistemic needs, and you can hold yourself to normative expectations to achieve epistemic ends. More than this, doing so is arguably a sign of secure self-esteem (Jordan et al. 2003; Tanesini 2020).

The second step to showing that you can have a trust relationship with yourself is to argue that you can accept your own epistemic trust. So we'll turn now to the psychological and normative features of a trustee who accepts trust. Consider the psychological 
feature $\left(\mathrm{i}^{\star}\right)$, that the trustee cares about the truster or his needs. This can obtain when you are both trustee and truster. You can willingly take on projects to meet your own needs, and do so because you care about yourself or those needs. This sort of self-care can be a component of healthy self-esteem, at least provided you can turn down overly harsh demands on yourself, such as working to the point of burnout. What about (ii $\left.{ }^{\star}\right)$, the normative feature of accepting trust? This can also obtain for yourself qua trustee: you can commit to doing your best for yourself, being subject to self-censure should you let yourself down or to self-congratulation or self-gratitude should you come through.

These points hold for epistemic trust, whether for representational or recognitional goods. Consider the psychological feature $\left(\mathrm{i}^{\star}\right)$ of the trustee who accepts epistemic trust. You can respond caringly to your need for knowledge or evidence by (say) doing careful research; and you can respond caringly to your need for epistemic recognition by (say) carefully vetting potential hearers of your testimony, or by self-coaching to express yourself confidently. Now consider the normative feature, (ii ${ }^{*}$ ), of the trustee who accepts epistemic trust. You can commit to coming through with the information that you need (say) to make an important decision, being subject to self-censure should you fail; and you can commit to coming through with the epistemic recognition that you need to perform well in that professional talk.

I conclude that relationships of epistemic self-trust are psychologically possible. More than this, they are part of a healthy and integrated relationship with oneself.

\section{Self-trust is more epistemically efficacious than (mere) self-reliance}

I argued that obtaining epistemic goods requires relying on yourself, not just your faculties, and that it is psychologically possible, indeed healthy, for this self-reliance to be part of a relationship of epistemic trust with yourself. I will finish by arguing that (a relationship of) epistemic self-trust is much better suited than mere epistemic selfreliance to securing epistemic goods. In other words, the efficacy-of-trust claim applies to epistemic self-trust too.

To draw this contrast between epistemic self-trust and (mere) epistemic self-reliance, we must flesh out the idea of mere self-reliance in general. For it might seem psychologically impossible to rely on oneself without trusting oneself - that is, to be the object of self-reliance without caring or committing to oneself. But it is possible. To see how, recall that it is possible to merely rely on a person: you simply premise your actions on her acting in some predictable way, where your interests would be harmed if she did not. You do not suppose that she will do so out of care for you or your projects, and you do not expect of her that she will do so. (At least, you do not expect this of her where the norms at issue are the norms of trust; you might still expect it of her because of other norms, such as legal ones.) And recall that it is possible to be relied on without caring about the person relying on you or about his needs, and without committing to do what he is relying on you for.

The same holds for a relationship of reliance within the self. Consider yourself first as the relier. You can certainly lack the two features of trust, yet still premise your actions on the prospect that you (qua reliee) will do something. Take the psychological feature (i). When you merely rely on yourself, you do not work from the supposition that you will perform the action in question out of care for your own needs. For example, you might lack self-esteem, not thinking that you or your needs are worth caring about. As for the normative feature (ii), you might not normatively expect yourself to do your best to meet your needs. Why not? Perhaps you do not feel yourself to be worth the commitment that doing this involves. 
So a person's relationship of self-reliance can fail to be one of self-trust because she lacks the psychological and normative features of a truster. It can also fail because she lacks the features of a trustee who accepts trust. It is possible to not particularly care about oneself or one's needs (feature $\left(i^{*}\right)$ ), for example if one suffers from depression or low self-esteem. And it is possible, for the same reasons, to resist or be indifferent to any normative pressure to meet your own needs (feature (ii $\left.{ }^{*}\right)$ ). Indeed, there is a good chance that, if you yourself qua relier are pessimistic about your own willingness or competence to do these things, this pessimism is well placed. Who would gauge your own psychological and normative dispositions better than you yourself? So it is possible to have a relationship of mere reliance with oneself.

A relationship of mere self-reliance is also possible in the epistemic case. Consider representational goods. You can rely on yourself for these without supposing yourself to care about (feature (i)), or be committed to (feature (ii)), securing them for yourself. And qua reliee, you can fail to care about your need for representational goods (feature $\left(\mathrm{i}^{*}\right)$ ) or to commit to securing them (feature $\left(\mathrm{ii}^{*}\right)$ ). Think of a child who does his homework not because he wants to learn, but because he has to, and does the bare minimum he thinks he can get away with. The same holds for recognitional epistemic goods. You can rely on yourself for epistemic recognition without supposing yourself to care about it (feature (i)) or be committed to providing it (feature (ii)); and you can fail to care about (feature $\left(\mathrm{ii}^{*}\right)$ ) or be committed to recognizing yourself epistemically (feature $\left(i^{\star}\right)$ ). For example, you might speak publicly because you have to, without recognizing yourself as having important things to say: you might have been called as a reluctant witness in a court case. Mere self-reliance, including for epistemic ends, is a psychological possibility.

It will come as little surprise that mere epistemic self-reliance tends not to be as efficacious as epistemic self-trust at securing epistemic ends. I have laid the groundwork for this claim already. Recall the efficacy-of-trust claim from section 2.2: in general, if you are in a relationship of trust with another person with respect to some end, you are apt to obtain that end more effectively by having a relationship of trust with her than by merely relying on her for it. I will now show that this applies when the party being trusted is oneself, and when the end in question is an epistemic good. I'll call this the efficacy-of-epistemic-self-trust claim.

The first step is to note that epistemic goods - with some exceptions, like simple perceptual knowledge - are often difficult to secure. Consider representational goods. We saw that epistemic responsibility is often important for obtaining these, and that epistemic responsibility is not for the faint-hearted. It requires epistemic virtues and skills, such as paying careful attention to evidence, believing in accord with good rather than motivated reasoning, being ready to challenge your worldview, and so forth. Similarly, obtaining epistemic recognition requires virtues and skills. Deserving it to begin with usually requires epistemic responsibility. And you need virtues such as epistemic courage to stick up for what you know even when it is unpopular, to insist on your due credit when those more powerful might try to usurp it, to speak up when others are speaking over you, or to exorcise the demons of low epistemic self-esteem. Such activities - whether in pursuit of representational or recognitional goods - do not typically come for free, but require passionate commitment, persistence, and skill.

The person who trusts herself is better placed to meet this challenge than the person who merely relies on herself. The reasons are special cases of those given in section 2.2, where I argued that trusting someone else tends to be more effective than merely relying on her. All we need do is show how these reasons apply in the case of epistemic self-trust.

The first reason, to recall, draws on the two features of accepting trust, caring for the trustee or his need (feature $\left(i^{\star}\right)$ ), and making yourself answerable to normative pressure 
to meet it (feature $\left(\mathrm{ii}^{*}\right)$ ). Both features dispose a trustee more strongly toward bringing about the end for which she is being trusted. This holds in the case of self-trust - i.e. when you are both truster and trustee, including when the need in question is epistemic. Take the psychological feature of accepting trust, $\left(\mathrm{i}^{\star}\right)$. If you care about your own need for representational epistemic goods, you will be more motivated than otherwise to exercise epistemic responsibility and do other things that facilitate securing them. And if you care about your need for epistemic recognition, you will be more prone than otherwise to behaving in ways geared to securing it - such as (once more) exercising epistemic responsibility, this time so that you deserve epistemic recognition, or persevering confidently when others interrupt you or belittle your contributions.

Now consider the normative feature of accepting trust, (ii ${ }^{*}$. If you have placed yourself under the norms of trust, you will be motivated to avoid letting yourself down. As a result, in search of representational epistemic goods you will (for example) exercise epistemic responsibility more scrupulously than you might otherwise, and in search of recognitional goods you will (for example) exercise greater discernment about whom you tell what to than you might otherwise, and you will be more prone to acknowledging your own epistemic strengths. In summary, the first reason why trust in others strongly tends to be more effective than mere reliance also applies to trust in oneself for epistemic goods: the psychological and normative features of the person who accepts epistemic self-trust dispose her to come through.

Let's turn to the second reason for the efficacy of trust over mere reliance: being trusted motivates a person to be trustworthy - both to accept the trust to begin with, and to come through once she has. It does this, as we saw, by signaling that the truster regards her as trustworthy, influencing her behavior by influencing her self-concept. If trust can exert this sort of influence from one person to another, it can surely do so within the psyche of a single person, including for epistemic ends. Trusting yourself encourages you, qua trustee, to conform to the positive self-concept signaled by this trust, that of a trustworthy person. That is, acting on the assumption that you will meet your own needs because you care about yourself, and holding yourself to normative expectations to do so, influences you to see yourself as trustworthy for these needs, and in turn behave accordingly (Harmon-Jones 2019: Chapter 1). Indeed, this is precisely why personal coaches and therapists encourage us to trust ourselves.

This holds when it is epistemic goods that you are trusting yourself for. Consider representational goods. If you treat yourself as someone who cares about meeting your need for knowledge and who is competent to do so, you will foster a corresponding self-concept. This in turn will help you conform to the image of an epistemically trustworthy person and act accordingly. The same holds for self-trust for epistemic recognition. If you treat yourself as someone who cares about your own need for epistemic recognition, and who is competent to give it when it is due, then you will foster a corresponding self-concept and act accordingly, say by acknowledging your cognitive accomplishments to yourself and not settling for less than appropriate acknowledgment from others.

Recall finally the third reason for the efficacy-of-trust claim: that when trust is conspicuously absent, it can signal distrust and hence lower the probability that the other party will be trustworthy. An analogous point applies when the other party is oneself and the ends are epistemic. Assuming that it is healthy and good to have a relationship of trust with oneself, ${ }^{12}$ merely relying on yourself is a case in which trust is

\footnotetext{
${ }^{12}$ Another possibility arises when you do trust yourself but you do not accept your own trust, or when you are willing to accept your own trust but you do not trust yourself. Space prohibits considering such cases here.
} 
conspicuously absent. It is apt to foster a self-concept of someone who does not care about yourself or your epistemic needs, or who does not regard these as worth a normative commitment. This self-concept is apt to be a self-fulfilling prophecy, siphoning your motivation to care for or commit to yourself, including for epistemic ends. This dynamic will work against any motivational advantages that you might otherwise have gained from putting in place mechanisms of pressure or self-coercion - though if you do trust yourself, such mechanisms might act as a positive reminder or encouragement to stay the course. So epistemic self-trust strongly tends to be more effective at securing epistemic ends than (mere) epistemic self-reliance.

In summary, epistemic self-trust is more effective at securing epistemic ends than (mere) epistemic self-reliance. The first reason is that accepting your own epistemic trust entails having psychological and normative features that raise the probability that you will come through. The second reason is that trusting yourself epistemically makes you more likely to be epistemically trustworthy. The third is that merely relying on yourself signals distrust in yourself and influences you to act accordingly.

\section{Conclusion}

Reliance on our cognitive faculties is crucial to our epistemic lives. But it is not the same as epistemic self-trust. Epistemic self-trust, like epistemic trust in others, involves a relationship of care under the auspices of normative expectations. We trust ourselves to be epistemically responsible in securing representational epistemic goods such as knowledge, and to exercise discernment in securing recognitional epistemic goods, including from ourselves. And we accept our own trust for these goods, caring about our own needs and striving to meet our own normative expectations. A relationship of epistemic self-trust is a healthy sign of robust self-esteem - and tends to be far more effective at securing epistemic ends.

Yet epistemic trust in oneself has been neglected, with more theoretical attention going to (mere) reliance on one's cognitive faculties. This trend should be stopped. Reliance on our cognitive faculties is epistemically efficacious only to the extent that the person at their helm epistemically trusts herself to wield them well. ${ }^{13}$

\section{References}

Alfano M. (2016). 'Friendship and the Structure of Trust.' In A. Masala and J. Webber (eds), From Personality to Virtue, pp. 186-206. Oxford: Oxford University Press.

Alvarez M. (2010). 'Reasons for Action and Practical Reasoning.' Ratio XXIII(4), 355-73.

Baier A. (1986). 'Trust and Antitrust.' Ethics 96(2), 231-60.

Chabris C. and Simons D. (2011). The Invisible Gorilla and Other Ways Our Intuition Deceives Us. New York, NY: Crown.

Coleman J. (1990). Foundations of Social Theory. Cambridge, MA: Harvard University Press.

D’Cruz J. (2019). 'Humble Trust.' Philosophical Studies. https://doi.org/10.1007/s11098-018-1220-6.

Dormandy K. (ed.) (2020). 'Exploitative Epistemic Trust.' In Trust in Epistemology, pp. 241-64. New York, NY: Routledge.

Faulkner P. (2007). 'On Telling and Trusting.' Mind 116(464), 875-902.

Foley R. (2001). Intellectual Trust in Oneself and Others. Cambridge: Cambridge University Press.

Fricker E. (2016). 'Doing (Better) What Comes Naturally: Zagzebski on Rationality and Epistemic Self-Trust.' Episteme 13(2), 151-66.

Hardin R. (1993). 'The Street-Level Epistemology of Trust.' Politics and Society 21(4), 505-29.

\footnotetext{
${ }^{13}$ Many thanks for helpful comments go to the anonymous reviewer for Episteme, and for helpful discussion to Heidi Grasswick, Christoph Jäger, and the participants of the 2019 Bled Epistemology Conference.
} 
Harmon-Jones E. (2019). Cognitive Dissonance: Reexamining a Pivotal Theory in Psychology. 2nd edn. Washington, DC: American Psychological Association.

Hawley K. (2014). 'Trust, Distrust and Commitment.' Noûs 48(1), 1-20.

Hieronymi P. (2008). 'The Reasons of Trust.' Australasian Journal of Philosophy 86(2), 213-36.

Hinchman E. (2005). 'Telling as Inviting to Trust.' Philosophy and Phenomenological Research 70 (3), 562-87.

Hinchman E. (2012). 'Can Trust Itself Ground a Reason to Believe the Trusted?' Abstracta 6(Special Issue VI), 47-83.

Holton R. (1994). 'Deciding to Trust, Coming to Believe.' Australasian Journal of Philosophy 72(1), 63-76.

Jones K. (1996). 'Trust as an Affective Attitude.' Ethics 107(1), 4-25.

Jones K. (2017). “But I Was Counting on You!” In P. Faulkner and T. Simpson (eds), The Philosophy of Trust, 90-108. Oxford: Oxford University Press.

Jordan C.H., Spencer S.J., Zanna M.P., Hoshino-Browne E. and Correll J. (2003). 'Secure and Defensive High Self-Esteem.' Journal of Personality and Social Psychology 85(5), 969-78.

Keren A. (2014). 'Trust and Belief: A Preemptive Reasons Account.' Synthese 191(12), 2593-615.

McMyler B. (2011). Testimony, Trust, and Authority. Oxford: Oxford University Press.

Nickel P.J. (2012). 'Trust and Testimony.' Pacific Philosophical Quarterly 93(3), 301-16.

Tanesini A. (2020). 'Virtuous and Vicious Intellectual Self-Trust.' In K. Dormandy (ed.), Trust in Epistemology, pp. 218-38. New York, NY: Routledge.

Zagzebski L. (2012). Epistemic Authority: A Theory of Trust, Authority, and Autonomy in Belief. Oxford: Oxford University Press.

Zeimbekis J. and Raftopoulos A. (2015). The Cognitive Penetrability of Perception: New Philosophical Perspectives. Oxford: Oxford University Press.

Katherine Dormandy is a Professor of Philosophy at the University of Innsbruck. Her primary research areas are epistemology, the philosophy of trust, and the philosophy of religion.

Cite this article: Dormandy K (2020). Epistemic Self-Trust: It's Personal. Episteme 1-16. https://doi.org/ 10.1017/epi.2020.49 